\title{
Teaching as Abductive Reasoning: The Role of Argumentation
}

\section{Chrysi RAPANTA}

\author{
Reasoning and Argumentation Lab \\ Institute of Philosophy \\ Universidade Nova de Lisboa (IFILNOVA) \\ Lisbon, Portugal \\ crapanta@fcsh.unl.pt
}

\begin{abstract}
The view that argumentation is a desired reasoning practice in the classroom is well reported in the literature. Nonetheless, it is still not clear what type of reasoning supports classroom argumentation. The paper discusses abductive reasoning as the most adequate for students' arguments to emerge in a classroom discussion. Abductive reasoning embraces the idea of plausibility and defeasibility of both the premises and the conclusion. As such, the teachers' role becomes one of guiding students through formulating relevant hypotheses and selecting the most plausible one according to criteria. Argumentation schemes are proposed as useful tools in this process.
\end{abstract}

Résumé: L'idée que l'argumentation est une pratique de raisonnement souhaitée en classe est bien documentée dans la littérature. Néanmoins, il n'est toujours pas clair quel type de raisonnement soutient l'argumentation en classe. Dans cet article on discute du raisonnement abductif comme étant le plus adéquat pour que les arguments des élèves émergent dans une discussion en classe. Le raisonnement abductif emploie l'idée de plausibilité et de la révocabilité des prémisses et de la conclusion. En tant que tel, le rôle des enseignants consiste à guider les élèves à formuler des hypothèses pertinentes et à sélectionner le plus plausible selon des critères. Les schèmes d'argumentation sont proposés comme des outils utiles dans ce processus.

Keywords: abductive reasoning; argumentation; education; teachers

\section{Introduction}

The relation between argumentation and education has been vastly explored during the last decades (Rapanta and Macagno 2016; Chinn 2006; Clark and Sampson et al. 2007; Erduran and Jimenez-

(C) Chrysi Rapanta. Informal Logic, Vol. 38, No. 2 (2018), pp. 293-311. 
Aleixandre 2008; Muller-Mirza and Perret-Clermont 2009). Much emphasis has been placed on the types of skills or strategies that both teachers and students may adopt for constructive dialogical argumentation in the classroom to take place (Rapanta, Garcia-Mila and Gilabert 2013; Felton, Garcia-Mila, et al. 2015; Kuhn, Hemberger and Khait 2014). Although argumentation and reasoning are not equivalent, their relation is indisputable due to the necessary condition that any argument, as a product of argumentation, shall be based on inference, as a product of reasoning (Mercier and Sperber 2011; Voss and Means 1991).

The present essay focuses on this three-fold relationship between reasoning, education, and argumentation, providing wellestablished theories of reasoning and argumentation as the basis of justification for a pedagogical mode of teaching based on logical inferences. Moreover, it is claimed that the nature of these inferences is mainly abductive, and their structure may be sought for in existing reasoning representations, such as the one provided by the so-called argumentation schemes (Walton 1996; Walton Reed and Macagno 2008).

\section{Abductive reasoning}

In a definition attributed to the philosopher Charles Peirce, cited in (Psillos 2011), "reasoning is a process in which the reasoner is conscious that a judgment, the conclusion, is determined by other judgment or judgments, the premises, according to a general habit of thought" (pp. 121-122). This general habit of thought, or rule of reasoning, must be truth-conducive, and truth must be based on knowledge and justification. In general, there are two ways in which a process of reasoning can confer justification on a belief. The first is by making the case that if the premises are true, the conclusion must be true. The second is by rendering a belief plausible and thus making it available for further testing (Psillos 2011). According to Peirce (1878), only the second way, which is called abduction or abductive reasoning, may produce new knowledge, and thus may be related to scientific reasoning. 
The difference between deduction, induction and abduction is well illustrated in the example given by Preyer and Mans cited in (Walton 2001) as presented in Table 1.

\begin{tabular}{|l|l|l|}
\hline Deductive & Inductive & Abductive \\
\hline $\begin{array}{l}\text { Suppose a bag contains } \\
\text { only red marbles, and } \\
\text { you take one out. You } \\
\text { may infer that the } \\
\text { marble is red. }\end{array}$ & $\begin{array}{l}\text { Suppose you do not } \\
\text { know the color of the } \\
\text { marbles in the bag, and } \\
\text { you take one out and it is } \\
\text { red. You may infer that } \\
\text { all the marbles in the bag } \\
\text { are red. }\end{array}$ & $\begin{array}{l}\text { Suppose you find a red } \\
\text { marble in the vicinity } \\
\text { You may infer that the } \\
\text { marble is from the bag. }\end{array}$ \\
\hline
\end{tabular}

Table 1. Distinction between deductive, inductive and abductive reasoning (Walton 2001)

For Walton (2001), abduction is different than deduction and induction because the conclusion is just a hypothesis, a best guess, based on the given knowledge and evidence at that moment. For this reason, abductive inferences are defeasible, meaning that they are "subject to retraction if further investigation of the facts in the case shows that another of the alternative explanations is "better"' (p. 145). Moreover, abductive reasoning resembles a continuous deliberation process that needs to be open to revision as new evidence of the factual circumstances of the case enters into the calculations. Abductive reasoning is similar to the reasoning of a detective looking for the best data that would give the best explanation possible. The decision for what counts as the best explanation in a given context is based on the criterion of plausibility, rather than possibility, as in deductive inferences, or probability, as in most inductive inferences (Walton, 2001).

According to the general definition of reasoning stated in the very beginning of this article, any inference must lead to some type of truth, or better said, true knowledge. In both deductive and inductive inferences, although the knowledge is true as it refers to facts, it is not novel knowledge, and as such, it does not require further justification. On the other hand, abductive reasoning is the only one that leads to new knowledge, and as such it needs further justification, using deductive, inductive or even additional abduc- 
tive reasoning. In this sense, abductive reasoning is the most complete type of reasoning, including all types of inferences that are possible to emerge both in everyday life and in science. First of all, it relates to deduction, as abductive reasoning is mainly about reasoning from effect to cause. However, what counts as cause in abductive reasoning is much broader than a deductive cause, because they are causes selected based on hypotheses (Josephson and Josephson 1996). Second, abduction may include induction, because it is through abductive reasoning that the claim that "all A's are B' $s$ " is considered a better, more plausible hypothesis based on the given evidence that "at least generally A's are B's"' (p. 19).

For these reasons, abductive reasoning has been highly valued as a different type of reasoning which: May be used as a general umbrella for all types of plausible inferences when it comes to arriving at the best explanation for a phenomenon or event, may produce novel knowledge, and may represent scientific reasoning at least when it comes to the discovery phase (Josephson and Josephson 1996; Peirce 1931; Walton 2005). However, its relation to and use for teaching has not been explicitly brought to light. Given the increasing evidence that students' quality of argumentative reasoning is generally low (Rapanta and Walton 2016; Glassner and Schwarz 2007; Kuhn, Goh et al. 2008), any attempt to apply knowledge from the field of reasoning and argumentation theory in education is extremely valuable (Rapanta and Macagno 2016). This is most pertinent to current society, as life situations become more and more fluid and ask for the consideration of multiple factors before arriving at a conclusion or a decision.

The goal of this article is to show that the use of reasoning in pedagogical contexts, especially in the form of scientific argumentation, resembles abductive reasoning more than any other type of reasoning described so far. This being the case, providing teachers with tools to help them identify, assess, and use abductive reasoning in the classroom in an argumentative manner is an urgent need.

\footnotetext{
${ }^{1}$ This is the alternative proposed by Josephson \& Josephson (1996) to replace the "All observed A's are B's", commonly used as the first part of an inductive inference.

(C) Chrysi Rapanta. Informal Logic, Vol. 38, No. 2 (2018), pp. 293-311.
} 
These tools shall mainly emerge from the field of argumentation theory, given the broadly investigated relation between abductive reasoning and dialogical argumentation (Macagno 2012; Walton 2001; Walton et al. 2008; Walton 2005).

\section{Abduction, scientific argumentation, and learning}

Argumentation, as treated by the majority of educational researchers, refers to a socio-cognitive activity, strongly related to learning. It is a cognitive activity, as it uses argument elements in order to defend a standpoint in such a way that becomes acceptable to a critic. This last point forms the basis of a critical discussion as proposed by the pragma-dialectical theory (see, for example, van Eemeren Grootendorst and Snoeck-Henkemans 2002). Regarding argument elements, Toulmin (1958) proposed the following six: claim, data, warrant, backing, rebuttal, and qualifier(s). Argumentation is also a social activity because in advancing argumentation one communicates with another in order to change his/her mind (Kim and Song 2006).

Many educational theorists support the view that argumentation or argumentative reasoning is a way of learning. Jean Piaget, in his early works, distinguishes between three types of interaction with children that contribute to cognitive development: The egocentric monologue, the constraint discourse, and the cooperation type. It is only in the last stage where genuine arguments emerge, and where logical proof and justification are encouraged in a context of shared reference, reflection, and mutual autonomy. Later on, Lev Vygotsky and his followers insisted on the idea of internalization of learned contents as a result of interaction with social actors. This learning in interaction has great chances to be argumentative, given that meaning is negotiated either as a process of knowledge coconstruction or in the form of a dialectical monologue.

A contemporary educational researcher and theorist who explained the relationship between argumentation and learning is Deanna Kuhn. According to Kuhn $(1992,2010)$, all learning can be conceptualized as argument. Specifically, she related science learning to science argumentation, developing the view of teaching and learning science as argument. Moreover, Kuhn summarized the 
vast empirical developmental research on the effects of dialogical argumentation on learning, claiming that "the first and most crucial development we look for is an increase in students' ability and willingness to attend critically to the other's dialogue" (Kuhn 2010, p. 816). Among the three types of reasoning, i.e., deductive, inductive and abductive, only abductive is dialogical, and thus potentially argumentative. As Walton (2005) puts it, "when abductive reasoning is used, the dialogue must be regarded as open to new evidence and future developments as the dialogue proceeds" (p. 234).

The large majority of researchers in Science agree that scientific reasoning is hypothetico-deductive, meaning that it is based on hypothesis formation, which is an abductive process. Lawson (2005), after presenting the main debate regarding whether scientific inquiry is more deductive, inductive, or something else, conveys the steps of human reasoning in both everyday and scientific contexts in the following: (1) Make an initial puzzling observation; (2) Use analogical reasoning, analogical transfer, or abduction to generate one or more hypotheses; (3) Suppose, through deduction, that the hypothesis under consideration is correct; (4) Test the hypothesis; (5) Compare predicted and observed results; and (6) Recycle the procedure until a hypothesis is generated, tested, and supported on one or more occasions and its competing alternatives have been tested and rejected.

Josephson and Josephson (1996) provide a task analysis framework of abductive hypothesis formation. According to these authors, "learning is the acquisition of knowledge. One main form of learning starts with wonder and ends in understanding. To understand something is to grasp an explanation of it" (pp. 28-29). Subsequently, learning science is about explaining the data. From this main task-goal, two subgoals emerge: generate elementary hypotheses, and form composite explanations (using those hypotheses). The generation of elementary hypotheses, which is the main part of the abductive reasoning process, can mainly be achieved through: a) evocation and b) instantiation. It is during instantiation that explanatory coverage and confidence values of the initial hypotheses are determined, re-determined, or refined. Figure 1 shows this process. 


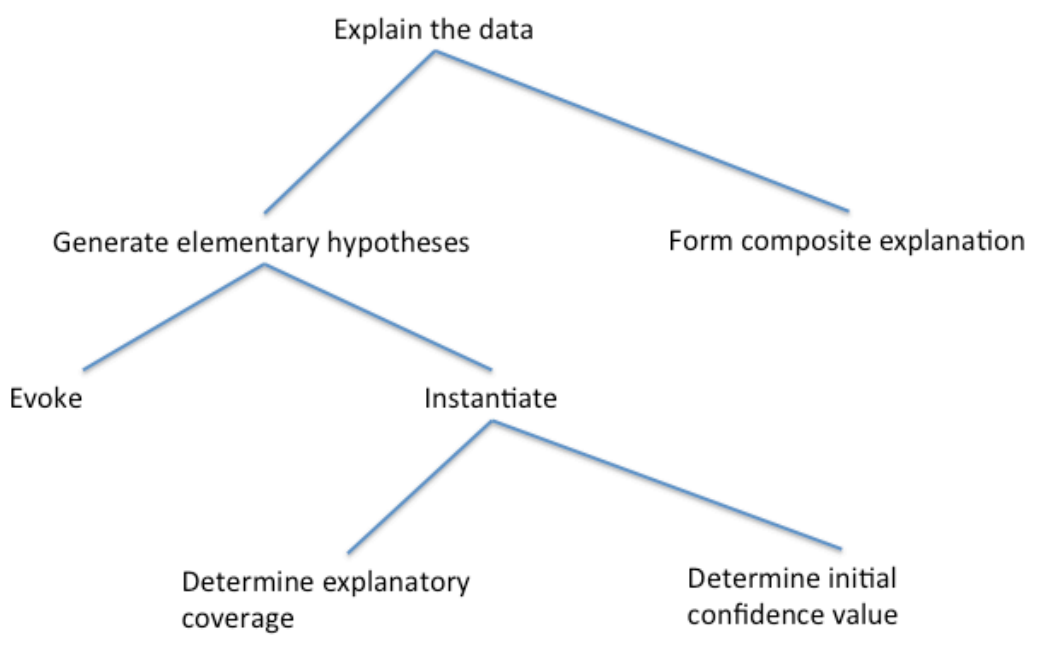

Figure 1. A framework for abductive reasoning (from Josephson and Josephson 1996; p. 140).

Transferring this model to a teaching and learning setting, at least two concepts merit our consideration. The first is that the main task of abduction should be the data explanation, so that hypotheses may be generated if the data allow for this to happen. What usually happens in a classroom, especially in a science classroom, is that the teacher explains the theory that is already decided by the scientific community as the most valid or acceptable. Instead, what Josephson and Josephson (1996) suggest is that it is the data, not the theories (usually composed of a claim plus data plus a warrant) that should be explained. We may further say that this "data" refers to both primary (available) and secondary (generated) data, which makes a lot of sense in science education, where students engage in an inquiry process formulating and testing hypotheses that potentially lead to new problems and questions. The second idea from the framework presented in Figure 1 is the distinction between "explanatory coverage" and "confidence value". It may remind us of Toulmin's (1958) distinction between "warrantusing" and "warrant-establishing" inferences. In the first case, the explanatory coverage is defined by the relationship between claim and data: Do the data processed so far, in the way they were processed (i.e., warrant), provide sufficient grounds for the initial 
claim-hypothesis? In the second case, the confidence value is defined by the relation between the backing of a theory and the backing of other existing or possible alternative theories: Does the backing provided so far for theory $a$ is sufficient for theory $a$ to be accepted as the best explanation?

The argument made in this section is: Given that a great part of learning is based on scientific reasoning, and scientific reasoning is mainly abductive, it can be further concluded that abductive reasoning is relevant to learning, and subsequently to the teaching and learning process. The next section presents examples of how abductive reasoning has been explicitly or implicitly treated thus far in educational research.

\section{Abduction as classroom argumentation}

Education practitioners have generally referred to teaching styles as being either inductive, i.e., presenting phenomena leading to principles, or deductive, i.e., presenting principles leading to phenomena (Felder and Silverman 1988). The inductive teaching strategies have also been presented as being a new and a more efficient way of promoting students' learning as they increase motivation. In socalled "inductive teaching", "the instructor begins by presenting students with a specific challenge, such as experimental data to interpret, a case study to analyze, or a complex real-world problem to solve" (Prince and Felder 2007, p. 14). Inquiry-based, discovery, and problem-based learning are examples of this broad category called inductive teaching. Induction here refers to the general idea of beginning with something concrete that students usually know in order to arrive at something more abstract, which is the general rule, theory, or principle that the teacher wants the students to learn. It is also contrasted with the traditional "deductive" teaching, in which students are taught theories and models first, and then progress to exercises and, more rarely, to real-life applications. Nonetheless, neither deduction nor induction as used in this sense provide us with any information of the type of reasoning that takes place in the classroom, and which subsequently leads to learning.

Using an abductive method of reasoning divided into different tasks, as in the framework presented in Figure 1, looks promising. 
However, to our knowledge, no explicit use of abductive reasoning has been reported thus far in science learning and teaching literature, with the exception of mathematics. Below I present three examples in which abduction was used, either explicitly or implicitly, as the main reasoning method while arguing in the classroom about a problem, issue, or phenomenon.

Abductive argumentation implies making use of rules that are not under complete control of the students, but which would seem more appropriate to justify a conclusion drawn from facts or information. Even though this type of argumentation does not seem to be compatible with teaching certain subjects where rules are very concrete and indisputable, such as math, it is still possible to use the abductive arguments initially used by the students and transform them, through guiding students' reasoning process, into the standardized validation rules. Of course for abductive arguments to be used, students should not have an idea of which theory must be used; "they look for a possible solution (...) they consider different cases, they explore, they seek different strategies" (Pedemonte 2007, p. 40). An example of a mathematical abductive argument in a collaborative problem-solving setting, i.e., students trying to find out why two triangles are equal, is described by (Pedemonte 2007, pp. 34-35). In that example, students $\left(12^{\text {th }}\right.$ and $13^{\text {th }}$ grade $)$ look for data to apply the congruence criterion and justify the congruence between the two triangles, as Table 2 shows.

\begin{tabular}{|l|l|}
\hline Student 1 & $\begin{array}{l}\text { The areas are always equal... with the calculator the areas } \\
\text { are equal. }\end{array}$ \\
\hline Student 2 & Now we have to see why! \\
\hline Student 1 & $\begin{array}{l}\text { We need to find how the base and the height change...if } \\
\text { there is a relationship that makes the area constant...The } \\
\text { area is constant...but I don't understand... so we have to } \\
\text { find 'base by height' congruent to 'base by height' of the } \\
\text { other triangle. }\end{array}$ \\
\hline Student 2 & If we take the constant bases and we change the heights... \\
\hline
\end{tabular}

Table 2. Example from abductive argumentation in mathematics (Pedemonte 2007, pp. 34-35).

Another large group of topics commonly selected to be used as prompts for argumentative discussions in the classroom are of a 
socio-scientific nature. More precisely, issues involving the application of science, for example, the use of animals for drug testing (Duschl and Osborne 2002). In this way, the role of argumentation is highlighted as a goal not only for science literacy, but also for citizenship education, and for a broader interdisciplinary literacy. Dawson and Venville (2010) describe an example of argumentation in which $10^{\text {th }}$ grade students argue about whether a couple who just performed a prenatal diagnosis for cystic fibrosis should be informed or not that the fetus was affected, but one of the alleles was not the baby's biological father. Table 3 presents an excerpt of the classroom argumentation that emerged, facilitated by the teacher.

\begin{tabular}{|l|l|}
\hline Student 1 & I think the counselor should tell both of them. \\
\hline Teacher & You'd tell them both. Why do you say that? \\
\hline Student 1 & Well because they have a right to know. [Many students talk.] \\
\hline Teacher & Hang on, [Student 2's name], once again, so we can all hear. \\
\hline Student 2 & $\begin{array}{l}\text { Well if the mum went to the clinic by herself, then obviously } \\
\text { she didn't want her husband to find out. }\end{array}$ \\
\hline Teacher & $\begin{array}{l}\text { I'm not sure it's that obvious though... we have a fairly hectic } \\
\text { and busy lifestyle...but it's still an idea. Thanks for that. }\end{array}$ \\
\hline Student 3 & $\begin{array}{l}\text { I'd tell the mother first and then I'd talk to her and ask if she } \\
\text { has like been cheating on her husband. Because, if you talk to } \\
\text { both at the same time you could ruin the relationship. Like if } \\
\text { you told them that like he wasn't the father, it could ruin the } \\
\text { relationship and it could just be a mutation. [Many students } \\
\text { comment.] }\end{array}$ \\
\hline Teacher & $\begin{array}{l}\text { What did we say the chances that a spontaneous mutation like } \\
\text { that can actually happen? }\end{array}$ \\
\hline Student 4 & $\begin{array}{l}\text { Isn't it like very, very slim, like the chances are one in a } \\
\text { billion, or one in a million? }\end{array}$ \\
\hline Student 5 & What if they both know that she's got another boyfriend? \\
\hline
\end{tabular}

Table 3. Classroom argumentation excerpt on a socioscientific issue (Dawson and Venville 2010, pp. 959-960)

The type of reasoning used in the example above, although not explicitly mentioned in the article, is abductive for the following reasons: a) it provides several hypothetical scenarios to explain what the best solution might be; b) these scenarios are not equally plausible (as the teacher's comments allow us to see); and c) the selection among the best explanatory hypotheses is based on the quality of justification provided for every argument, and the degree 
of plausibility of the premises involved. The only type of reasoning that is defeasible by nature due to its definition by plausibility is abductive reasoning (Walton 2001). Thus, the example above is very likely to be an example of abductive reasoning manifested in a sequence of argumentative interaction on a controversial topic in a science classroom.

This is also the case in many other attempts in which a science teacher reasons together with the students with the goal to promote some type of argumentation on the taught contents. Table 4 presents an example provided by Driver, Asoko et al. (1994), in which a teacher explored the notion of sunlight with his students. The main triggering questions or "puzzling observations" to use Lawson's (2005) term were "Where does the sunlight come from?" and "How does the sunlight get here?"

\begin{tabular}{|l|l|}
\hline Student 1 & From the Sun. \\
\hline Teacher & $\begin{array}{l}\text { You mean that the light that's coming through that window } \\
\text { has come from the Sun? (Several simultaneous replies). }\end{array}$ \\
\hline Student 2 & $\begin{array}{l}\text { It's from the heat - because it's so hot it makes a bright } \\
\text { light. }\end{array}$ \\
\hline Teacher & $\begin{array}{l}\text { So how does it get here? If the light is at the Sun, how } \\
\text { come it is here as well? Martyn? }\end{array}$ \\
\hline Student 3 & 'Cause the Sun's shining on us. \\
\hline Teacher & $\begin{array}{l}\text { But it is 93 million miles away - so how come the light } \\
\text { from the Sun is here on the table? }\end{array}$ \\
\hline Student 4 & Is it because of the ozone layer? \\
\hline Teacher & But how does the sunlight get here? \\
\hline Student 5 & It travels here. \\
\hline Teacher & $\begin{array}{l}\text { Coulton says, and his exact words are, that "it travels here". } \\
\text { In other words, light moves from the Sun to here... }\end{array}$ \\
\hline Student 5 & Yes. \\
\hline Teacher & 93 million miles. Is that right? \\
\hline Student 5 & Yes. \\
\hline
\end{tabular}

Table 4. Example of abductive argumentation in a science classroom (Driver et al. 1994, p. 9).

As previously mentioned, abduction is the only one of the three types of reasoning that creates new knowledge and thus provides a potential for learning. According to Magnani (2000), abduction

(C) Chrysi Rapanta. Informal Logic, Vol. 38, No. 2 (2018), pp. 293-311. 
mainly includes two parts or epistemological processes: the generation of plausible hypotheses, and the selection between them as resting on inference from the best explanation. In the example above, the teacher only uses the first part of abduction, allowing for many hypothetical scenarios to emerge. Later on, as we are informed by the article, the teacher leads the students to a series of experiments to confirm that light does travel, and moreover, it travels in straight lines over long distances. Thus, the decision on what represents the best explanation was based on experiments and testing, as implied by the hypothetico-deductive model of scientific reasoning. However, the discursive or argumentative part of science learning was only based on abductive reasoning.

Our goal here is not to analyze all instances of classroom argumentation reported in the literature to see whether or not they can be described in abductive reasoning terms (although that might be a potential aspect of future research). Our goal is rather to show that abductive reasoning plays an important role in scientific argumentation and it guides students' reasoning in an explicit, sociodiscursive context. This view is not contrary to the description of scientific reasoning as hypothetico-deductive, as, in the end, this is what scientific argumentation in the classroom consists of, especially when it is guided by the teacher: a series of hypothetical plausible explanatory scenarios until a conclusion that most resembles a scientific theory is reached. The problem arises when more scientific theories may apply and may be equally valid, from a deductive point of view, for the same phenomenon. What would the role of the teacher be then?

\section{The use of argumentation schemes for teaching}

To the question, "how we can better assist teachers in guiding students' reasoning and learning process?", a possible answer is: by using argumentation schemes and their corresponding critical questions. Argumentation schemes are forms of argument that enable us to identify and evaluate common types of argumentation in everyday discourse (Walton et al. 2008), including classroom discourse (Macagno and Konstantinidou 2013; Rapanta and Walton 2016). Critical questions, in general, are questions prompting criti- 
cal thinking, and their use as scaffolding tools in the classroom has been broad, especially in regards to argumentation (Chin and Osborne 2010; Mayweg-Paus, Thiebach and Jucks 2016). The combination of each argumentation scheme with a series of corresponding critical questions that are used to evaluate a given argument in a particular case (Walton et al. 2008), makes schemes useful tools for guiding research and practice in education and in other discursive contexts.

Not all argumentation schemes represent abductive reasoning, although one of their main uses is to model different kinds of plausible (abductive, presumptive, defeasible) arguments. For that, their structure mostly resembles what can be called a defeasible modus ponens structure, in which the conclusion is plausibly drawn from the premises (major, minor, conditional and other types of premises emerging from the critical questions) on the basis of how sufficiently those premises are addressed (Walton et al. 2008). This idea provides a new way of assessing and reconstructing arguments, and a new method for teachers to guide argumentation, which leads to the best (most plausible) theory available at the moment to explain certain data. Below is an example from Peirce given by (Walton and Reed 2005), adapted and reconstructed for the needs of this article as shown in Table 5, below.

The argument "If fossilized remains of fish were found on Mount Lemmon, then there were fish at Mount Lemmon at one time" can be a perfectly appropriate argument used by a teacher in a biology class. If the discourse stops there, it probably means that the teacher opts for adopting an authoritative teaching style, at least at that moment, without being willing to engage the students in an argumentative discussion on the issue of whether finding fish fossils on a mountain means that, most probably, the mountain was under water. However, the same argument, reconstructed as an abductive inference, as shown on Table 4, can provide space for further justification to take place, including the consideration of alternative theories, which is one of the main argument skills as stated in (Kuhn 1991). In addition, using the critical questions that emerge from the previously presented reconstruction, the teacher can play the "devil's advocate" while students try to find out the best explanation for the provided data.

(C) Chrysi Rapanta. Informal Logic, Vol. 38, No. 2 (2018), pp. 293-311. 


\begin{tabular}{|c|c|c|}
\hline Argument & $\begin{array}{l}\text { Argumentation } \\
\text { scheme }\end{array}$ & Critical questions \\
\hline \multirow[t]{3}{*}{$\begin{array}{l}\text { If fossilized remains of } \\
\text { fish were found on } \\
\text { Mount Lemmon, then } \\
\text { were fish at Mount } \\
\text { Lemmon at one time. }\end{array}$} & $\begin{array}{l}\text { Major premise: } \\
\text { Fossilized remains of } \\
\text { fish were found on } \\
\text { Mount Lemmon (D). }\end{array}$ & $\begin{array}{l}\text { Are there any other } \\
\text { data D that may con- } \\
\text { tradict or be used as } \\
\text { counter-evidence } \\
\text { against D? }\end{array}$ \\
\hline & $\begin{array}{l}\text { Minor premise: Fish } \\
\text { can only survive in } \\
\text { water (E). } \\
\text { Implicit premise: No } \\
\text { alternative explanation } \\
\mathrm{E}^{\prime} \text { given so far is as } \\
\text { satisfactory as E. }\end{array}$ & $\begin{array}{l}\text { Are there any other } \\
\text { ways that the fish may } \\
\text { have appeared there } \\
\text { apart from having lived } \\
\text { there? (examples of } \\
\text { alternative explana- } \\
\text { tions: transported there, } \\
\text { blown by hurricane). }\end{array}$ \\
\hline & $\begin{array}{l}\text { Conclusion: If there } \\
\text { were fish at Mount } \\
\text { Lemmon at one time, } \\
\text { then Mount Lemmon } \\
\text { was under water at one } \\
\text { time }(\mathrm{PH}) \text {. }\end{array}$ & $\begin{array}{l}\text { How satisfactory is this } \\
\text { plausible hypothesis } \\
\text { PH against other } \\
\text { hypotheses that may } \\
\text { derive from alternative } \\
\text { explanations? }\end{array}$ \\
\hline
\end{tabular}

Table 5. An argument represented as abductive argumentation scheme

\section{Conclusion}

In this article, it was shown how abductive, i.e., plausible and defeasible hypothetical reasoning, is and should be used as a main tool in guiding students' argumentation in the (science) classroom. Although many authors have talked about the nature and structure of this type of reasoning, its explicit relation with (science) education has not been placed in the spotlight. The present essay first explains the unique characteristics of abductive reasoning in relation to the other two very common types, i.e., deductive and inductive. Second, it presents examples from representative empirical research on students' argumentation showing that the nature of the explicit argumentation process in the classroom is mainly abductive. Third, it discusses the use of argumentation 
schemes with their corresponding critical questions as a tool for teachers to be able to reconstruct and support classroom argumentation.

One of the main concerns that can be raised regarding the proposal that abductive reasoning should be used more explicitly when teaching (with) argumentation is that not only contents and topics are offered for this type of reasoning in the same way that not all curriculum contents are offered for argumentation. Explanation is another predominant discursive activity in the classroom and in many cases contents should be explained rather than argued about. Another concern regards the theoretical model behind abductive reasoning that it is most adequate to guide teaching and learning practices based on abductive inferences. We suggested that the framework of tasks during abductive reasoning described by Josephson and Josephson (1996) is a good starting point for teachers to be able to connect learning tasks with reasoning steps. More work in this vein is needed. Argumentation schemes and their classification as being more related to one reasoning task-goal than another offer a promising direction.

Regardless of the concerns and limitations, which can be addressed with future research, the main idea of the article remains clear: given that education as a teaching and learning process is based on reasoning, it is of great importance to define what type of reasoning this should be. The view adopted in this article is that the answer may be found in the field of argumentation, as extensive empirical research shows that a type of reasoning generally called "argumentative reasoning" yields significantly positive results in terms of learning and reasoning quality. Nonetheless, it is still not clear what type of structure this reasoning should adopt for students to be able to argue, and subsequently to reason. To the degree that discourse reflects reasoning and vice versa, analyzing and assessing those discursive structures which represent the type of "good" (reflective, fruitful, valid) predominant reasoning in the classroom emerges as a first main need. Abductive reasoning is a good candidate for that, as it is tied not only to what is known but also to what is not known in a case, i.e., the "incomplete body of evidence" (Walton, 2001, p. 143). The role of teachers is, then, to guide students through the formulation of plausible hypotheses and the

(C) Chrysi Rapanta. Informal Logic, Vol. 38, No. 2 (2018), pp. 293-311. 
choice between them, forming valid justifications and adopting standards of critical questioning and thinking. Teacher training on abductive reasoning and argumentation is the second main need.

Acknowledgements: This work was possible thanks to a postdoctoral research grant (SFRH/BPD/109331/2015) granted to the author by the Portuguese Foundation for Science and Technology, and to an exploratory grant award from the Faculty of Social Sciences and Humanities.

\section{References}

Chin Christine and Jonathan Osborne. 2010. Students' questions and discursive interaction: Their impact on argumentation during collaborative group discussions in science. Journal of Research in Science Teaching 47(7): 883-908.

Chinn, Clark A. 2006. Learning to argue. In Collaborative learning, reasoning, and technology, eds. Angela O'Donnell, Cindy HmeloSilver, and Gijsbert Erkens, 355-383. Mahwah, NJ: Lawrence Erlbaum Publishers.

Clark Douglas B., Sampson Victor, Weinberger Armin and Gijsbert Erkens. 2007. Analytic frameworks for assessing dialogic argumentation in online learning environments. Educational Psychology Review 19(3): 343-374.

Dawson Vaille M. and Grady Venville. 2010. Teaching strategies for developing students' argumentation skills about socioscientific issues in high school genetics. Research in Science Education 40: 133-148.

Driver Rosalind, Asoko Hilary, Leach John, Mortimer Eduardo and Philip Scott. 1994. Constructing scientific knowledge in the classroom. Educational Researcher 23(7): 5-12.

Duschl Richard and Jonathan Osborne. 2002. Supporting and promoting argumentation discourse in science education. Studies in Science Education 38(1): 39-72.

van Eemeren Frans, Grootendorst Rob and Francisca SnoeckHenkemans. 2002. Argumentation: Analysis, evaluation, presentation. Mahwah, NJ: Lawrence Erlbaum Publishers.

Erduran Sibel and Maria-Pillar Jimenez-Aleixandre, eds. 2008. Argumentation in science education: perspectives from classroom-based research. Dordrecht: Springer. 
Felder Richard M. and Linda Silverman. 1988. Learning and teaching styles in engineering education. Engineering Education 78(7): 674681.

Felton Mark, Garcia-Mila Merce, Villarroel Costanza and Sandra Gilabert. 2015. Arguing collaboratively: Argumentative discourse types and their potential for knowledge building. British Journal of Educational Psychology 85(3): 372-386.

Glassner Armin and Baruch Schwarz. 2007. What stands and develops between creative and critical thinking? Argumentation? Thinking Skills \& Creativity 2(1): 10-18.

Josephson John and Susan Josephson. 1996. Abductive inference. Cambridge: Cambridge University Press.

Kim Heekyong and Jinwoong Song. 2006. The features of peer argumentation in middle school students' scientific inquiry. Research in Science Education 36(3): 211-233.

Kuhn Deanna. 1991. The skills of argument. New York: Cambridge University Press.

Kuhn Deanna. 1992. Thinking as argument. Harvard Educational Review 62(2): $155-178$

Kuhn Deanna. 2010. Teaching and learning science as argument. Science Education 94(5): 810-824.

Kuhn Deanna, Goh Wendy, Iordanou Kalypso, and David Shaenfield. 2008. Arguing on the computer: A microgenetic study of developing argument skills in a computer-supported environment. Child Development 79(5): 1310-1328.

Kuhn Deanna, Hemberger Laura, and Valerie Khait. 2014. Argue with me: Argument as a path to developing students' thinking and writing. New York: Wessex Press.

Lawson Anton E. 2005. What is the role of induction and deduction in reasoning and scientific inquiry? Journal of Research in Science Teaching 42(6): 716-740.

Macagno Fabrizio. 2012. Presumptive reasoning in interpretation. Implicatures and conflicts of presumptions. Argumentation 26(2): 233-265.

Macagno Fabrizio and Aikaterini Konstantinidou. 2013. What students' arguments can tell us: Using argumentation schemes in science education. Argumentation 27(3): 225-243.

Magnani Lorenzo. 2000. Abduction, reason and science: Processes of discovery and explanation. Dordrecht: Kluwer Academic Publishers.

Mayweg-Paus Elisabeth, Thiebach Monica and Regina Jucks. 2016. Let me critically question this!-Insights from a training study on the role

(C) Chrysi Rapanta. Informal Logic, Vol. 38, No. 2 (2018), pp. 293-311. 
of questioning in argumentative discourse. International Journal of Educational Researc 79: 195-210.

Mercier Hugo and Dan Sperber. 2011. Why do humans reason? Arguments for an argumentative theory. Behavioral and Brain Sciences 34(2): 57-74.

Muller-Mirza Nathalie and Anne-Nelly Perret-Clermont. 2009. Argumentation and education: Theoretical foundations and practices. Dordrecht etc.: Springer.

Pedemonte Bettina. 2007. How can the relationship between argumentation and proof be analysed? Educational Studies in Mathematics 66(1): 23-41.

Peirce Charles S. 1878. How to make our ideas clear. In The essential Peirce, eds. Nathan Houser and Christian Kloesel, Volume 1. Bloomington: Indiana University Press.

Peirce Charles S. 1931. Collected papers of Charles Sanders Peirce (C. Hartshorne, P. Weiss, and A. Burks, eds.). Cambridge MA: Belknap Press.

Prince Michael and Richard Felder. 2007. The many faces of inductive teaching and learning. Journal of College Science Teaching 36(5): 1420.

Psillos Stathis. 2011. An explorer upon untrodden ground: Peirce on abduction. In Handbook of the History of Logic, eds. Dov Gabbay, Stephan Hartmann and John Woods, 117-151. Oxford: NorthHolland.

Rapanta Chrysi, Garcia-Mila Merce, and Sandra Gilabert. 2013. What is meant by argumentative competence? An integrative review of methods of analysis and assessment in education. Review of Educational Research 83(4): 483-520.

Rapanta Chrysi and Fabrizio Macagno. 2016. Argumentation methods in educational contexts: Introduction to the special issue. International Journal of Educational Research 79: 142-149.

Rapanta Chrysi and Douglas Walton. The use of argument maps as an assessment tool in higher education. International Journal of Educational Research 79: 211-221.

Toulmin Stephen. 1958. The uses of argument. Cambridge: Cambridge University Press.

Voss James and Mary Means. 1991. Learning to reason via instruction in argumentation. Learning and Instruction 1(4): 337-350.

Walton Douglas. 2001a. Abductive, presumptive and plausible arguments. Informal Logic 21(2): 141-169. 
Walton Douglas. 2001b. Enthymemes, common knowledge, and plausible inference. Philosophy and Rhetoric 34(2): 93-112.

Walton Douglas. 2005. Abductive reasoning. Tuscaloosa: University of Alabama Press.

Walton Douglas and Chris Reed. 2005. Argumentation schemes and enthymemes. Synthese 145(3): 339-370.

Walton Douglas, Reed Chris and Fabrizio Macagno. 2008. Argumentation schemes. New York: Cambridge University Press. 